\title{
Early age performance evaluation of new-anti cracking functional materials of concrete on member scale
}

\author{
Ting Yao ${ }^{1, a}$, Yujiang Wang ${ }^{2, b}$, Qian Tian ${ }^{1, c}$, Wen $\mathrm{Xu}^{1, \mathrm{~d}}$ \\ ${ }^{1}$ State Key Laboratory of High Performance Civil Engineering Materials, Jiangsu Research Institute \\ of Building Science, Nanjing, 210008, China \\ ${ }^{2}$ College of Materials Science and Engineering, Southeast University, Nanjing 211189, China \\ ayaoting@cnjsjk.cn, byjwangjs@126.com, Tianqian@cnjsjk.cn, ${ }^{b}$ xuwen@cnjsjk.cn
}

Keywords: concrete, member scale, expansive agent, hydration heat regulation, new-anti cracking functional materials

\begin{abstract}
Early deformation cracking is a widespread problem in base concrete walls of high-rise building. In the view of material to solve concrete cracking at early age, new-anti cracking functional materials make it by reducing shrinkage and regulating hydration heat. In this paper, several groups of concrete members were designed to contrast the effect of the functional materials, and based on embedding sensors in concrete members, temperature evolutions and strain evolutions are obtained in outdoor. The results show that compared with reference concrete, the maximum temperature rise of concrete prepared with new-anti cracking functional materials not only was reduced, but only there are reasonably expansive deformation at early age which can compensate later shrinkage which will be very beneficial to inhibit cracking.
\end{abstract}

\section{Introduction}

Researches have shown that the possibility occurrence of cracks for basement slab is $10 \%$ in the all surveyed slab projects, while it's over $85 \%$ in all surveyed RC walls [1].However, a number of high-rise reinforcement concrete buildings have been conducted in recent years. Due to the demand of high seepage resistance and durability, cracking control of base restrained concrete walls of such engineering plays a very important role on construction quality.

It becomes more and more popular to use shrinkage-compensating concrete prepared with expansive agent, as an important ways to inhibit concrete structure cracking. However, the most researches on expansive agent focus on laboratory experiments, including the expansion mechanism [2-4] and stability [5-6] expansion rate [7-8] shrinkage-compensating efficiency [9-10], etc., though recently a few references were found about the field monitoring of base structures [11-13].In addition, few references were found about it for chemical admixture adjusting the hydration heating rate of cement (HR).

However, real-time temperature history and deformation history can be measured by field monitoring on macro scale, but for a certain practical structure, it's impossible to provide control group to compare the application effect of new-anti cracking functional materials properly. Besides, specimens in the lab usually are so small that there is no obvious temperature rise from hydration. Thus, in this paper several concrete members were designed to solve the problems above in order to simulate the heat environment of base wall.

\section{Experimental Campaign}

Geometry. An experiment monitoring for measuring early-age temperatures and strains on prismatic concrete members was carried out, satisfying the following condition: a) the prism is big enough so as to engender a heat generation potential to cause significant temperature and strain gradients similar to practical base wall, and b) meanwhile it should be small enough in order to be compatible with laboratory work. The dimensions of the concrete prism are $1 \mathrm{~m} \times 0.8 \mathrm{~m} \times 1 \mathrm{~m}$. Lateral faces and base of the prism were insulated with $2 \mathrm{~cm}$ thick plywood formwork. Concrete casting and 
the experimental procedures took place outside room to be in the atmospheric environment.

Materials. New-anti cracking functional materials include calcium expansive agent with low alkali and high efficiency (HME-III) and cracking resistant additive (HME-V). Here HME-V is prepared with HME-III and a new chemical admixture adjusting the hydration heating rate of cement (HR). HME-III is used to compensate shrinkage of concrete, whose property is shown in Table 1 . HR is a kind of polysaccharose substance with relative molecular mass of 3000-5000 which is faint yellow and odorless.

On the one hand, HME-V can regulate hydration rate of cement and delay cement hydration process, so that heat emission condition of structures can be fully applied to weaken temperature rise and temperature drop rate, which is helpful to reduce cracking risk due to temperature deformation; on the other hand, HME-V can adjust expansive history to make it effective for the capacity of compensating shrinkage of expansive agent in the high performance concrete structures $[14,15]$. HR is different from traditional retarding admixture, shown in Fig.1.

Table 1. Physicochemical characteristics of HME-III

\begin{tabular}{|c|c|c|}
\hline \multicolumn{2}{|c|}{ Content } & $\begin{array}{l}\text { Performance } \\
\text { index }\end{array}$ \\
\hline \multirow{3}{*}{\multicolumn{2}{|c|}{$\begin{array}{l}\text { Fineness(1.18mm sieve residue)/\% } \\
\text { Total alkali charge/\% } \\
\text { Amount of chloride ions/\% }\end{array}$}} & $\leq 0.50$ \\
\hline & & $\leq 0.60$ \\
\hline & & $\leq 0.05$ \\
\hline \multirow{2}{*}{ Setting time } & Initial setting & 170 \\
\hline & Final setting & 345 \\
\hline Restraint & 7 days in water & 0.031 \\
\hline expansion rate & 28 day in the air & -0.012 \\
\hline Compressive & $7 d$ & 32.2 \\
\hline Strength & $28 d$ & 48.7 \\
\hline
\end{tabular}

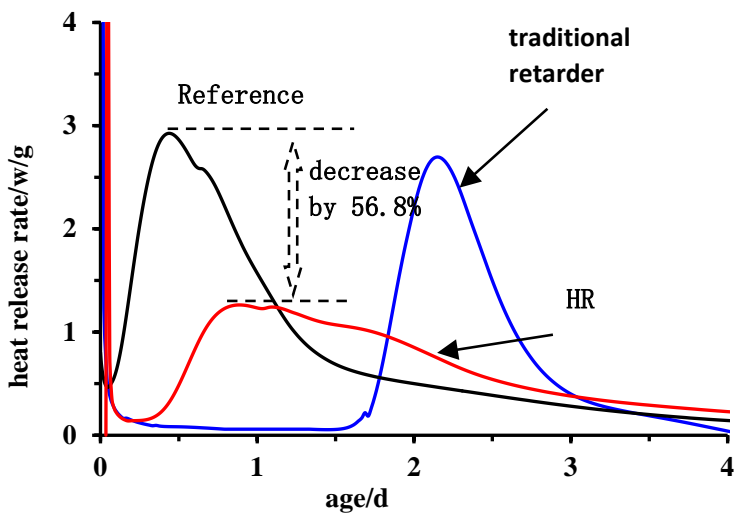

Figure 1. The curve of hydration heating rate of cement

Concretes mixtures proportions. Concrete grade C40, the impermeability grade P8 were prepared in the concrete prism, while cement type I P.O.42.5R is adopted. According to properties of raw material and trial mixture in the lab, concrete batches produced from the mix given in Table2 had slumps close to $120 \mathrm{~mm}$ to meet the pumping requirements.

Table 2. Concretes mixture proportions $\left(\mathrm{kg} / \mathrm{m}^{3}\right)$

\begin{tabular}{c|c|c|c|c|c|c|c|}
\hline \multirow{2}{*}{ No. } & \multicolumn{6}{|c|}{ Basic ratio $/ \mathrm{kg} / \mathrm{m}^{3}$} & New-anti cracking functional materials $/ \mathrm{kg} / \mathrm{m}^{3}$ \\
\cline { 2 - 8 } & C & FA & S & G & W & HME-III & HME-V \\
\hline 1\# & 320 & 90 & 753 & 1084 & 165 & & \\
\hline $2 \#$ & 320 & 82 & 753 & 1084 & 165 & 8.2 & 9.02 \\
3\# & 320 & 81 & 753 & 1084 & 165 & & \\
\hline
\end{tabular}

Monitoring. Unbounded elastic wire resistance type strain meters with internal resistive temperature sensor were used to monitor the strain and temperature behavior of the concrete (with a precision of $\pm 0.5^{\circ} \mathrm{C}$ ) at the same time and location. All these strain gages were embedded into concrete. Sensor positions are schematically shown in Fig.2.For every concrete member, these sensors were embedded at two positions, one in the $2 \mathrm{~cm}$ from lateral faces, and the other at the center. The mold were prepared with plywood formwork which can keep warm and be similar to thermal environment of wall. Installing of stain gauges were completed before pouring of the concrete. Data acquisition started after casting. Because concrete were not solidified just after concrete placing, the reference points for deformation were selected at final setting. 


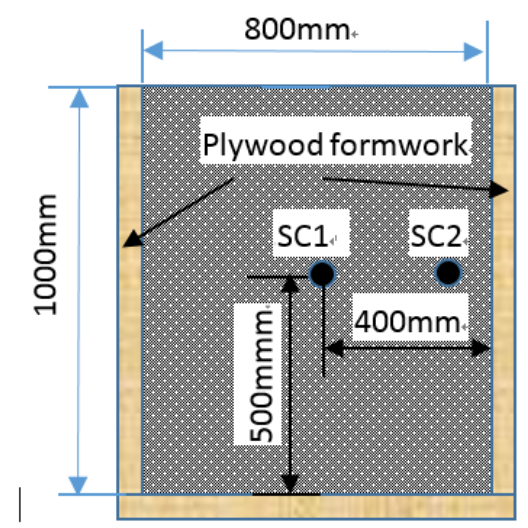

(a) Lateral view

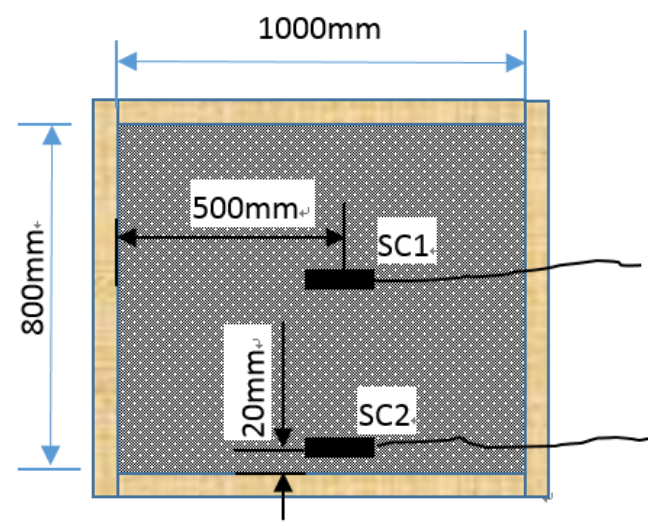

(b) Plan view

Fig.2 Experimental set-up: concrete and sensors location

\section{Discussion of results}

Temperature. Temperatures measured in the concrete members are presented in Fig.3-Fig.6. One can notice that, the temperature varied each other at different types and different locations, but their tendencies are accordant. As shown in the Fig.3-6, the heating period begins after concrete casting, and lasts for about 1 day to maximum value; it is then followed by the cooling period, and after 4 days thermal equilibrium is reached between the concrete elements and the climatic environment. The actual temperature varied continuously with the atmospheric temperature variance day by day, however, the farther the sensors were embedded away from the edge of the concrete members, and the smaller concrete temperature was impacted.

The figures also show that there are obvious peak temperature rises about $28^{\circ} \mathrm{C}$ at the point SC1 and $19^{\circ} \mathrm{Cat}$ the point SC2 because of cement hydration, and temperature values at the center are more than these on the edge. Due to late setting time, $3 \#$ caught up with the rise of air temperature up to $13.2^{\circ} \mathrm{C}$, so that it only decreased by $2.4^{\circ} \mathrm{Ccompared}$ with $1 \#$ and $2 \#$, which means that $3 \#$ could have a lower temperature rise if there is no influence of air temperature. We also can see the effect of environment from Fig.5 and fig.6 because 1\# and 2\# nearly have another temperature peaks, different from 3\#. Thus, in contrast with reference concrete, there is an obvious temperature peak drop for these concrete prepared with chemical admixture adjusting the hydration heating rate of cement.
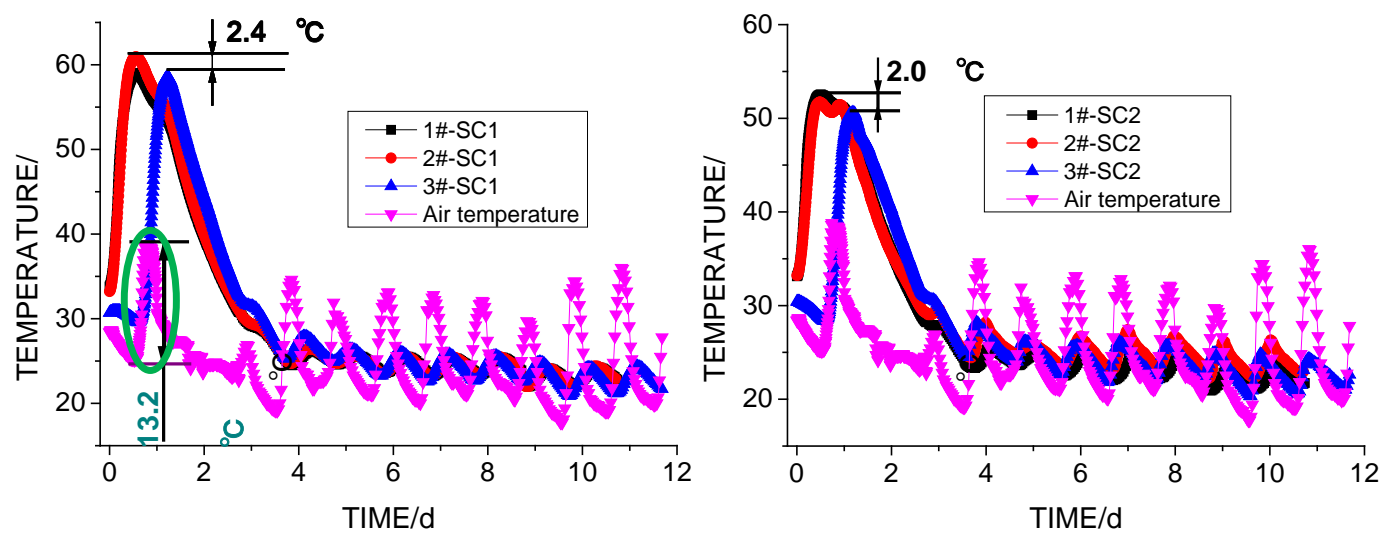

Fig.3 Temperature curves at the center of members Fig.4 Temperature curves on the edge of members 

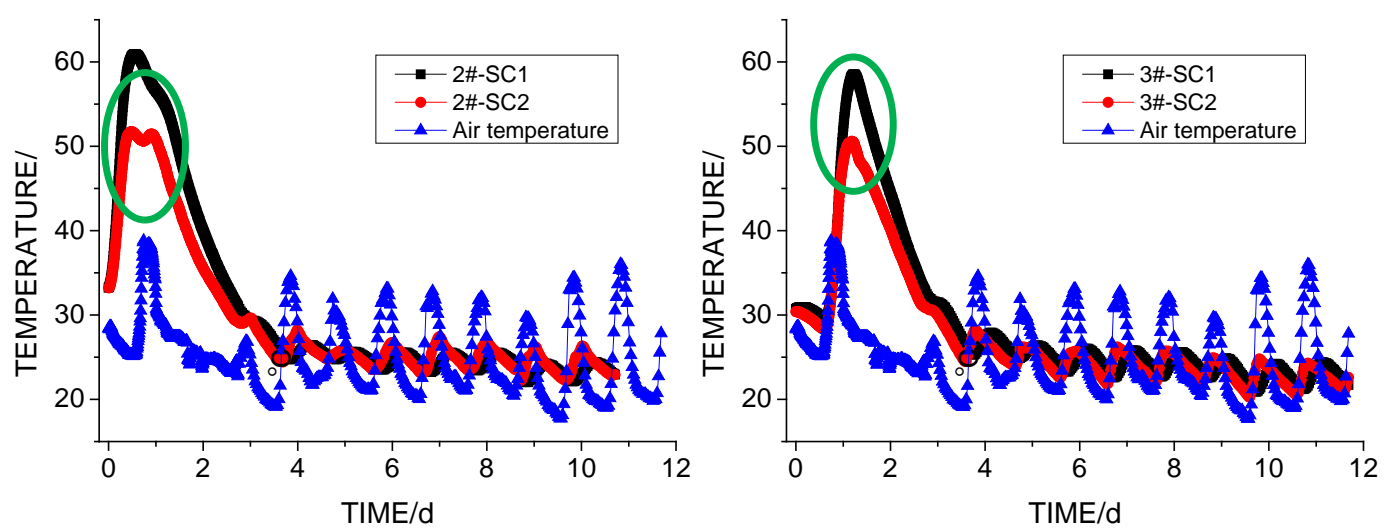

Fig.5 Temperature curves at different location (2\#)

Fig.6 Temperature curves at different location (3\#)

Deformation.The strain history were illustrated in Fig.7-Fig.10. The results point out thatthe expectable tendency was confirmed after final setting of concrete. The sensors recorded different peak expansions because of different peak temperature and the effect of expansive agent in one day, therefore concrete members expand at the heating phase, while shrinking at the cooling phase. As shown in Fig.7 and fig.8, on the whole, for concrete members 2\# and 3\# with expansive agent, strains were bigger than reference concrete, about $112 \mu \varepsilon$ and $83 \mu \varepsilon$, respectively, so we can see concrete mixing expansive agent can generate a certain amount of expansion at early age, so that shrinkage decreased at late age, and they are about $88 \mu \varepsilon$, much less than $200 \mu \varepsilon$ in 1\#.In addition, from Fig. 9 and Fig.10, one can notice that there are very slightly differences about strain between the edge and center of the concrete members. Thus, from these strain results, it's not difficult to know that, because there was a certain expansion at early age, it can be considered as compensating shrinkage caused at late age in a certain extent so as to inhibit cracking.

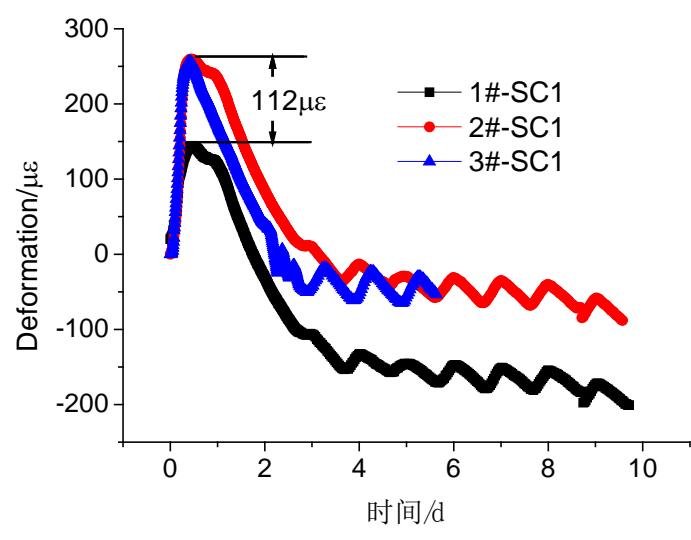

Fig.7 Strain curves at the member center

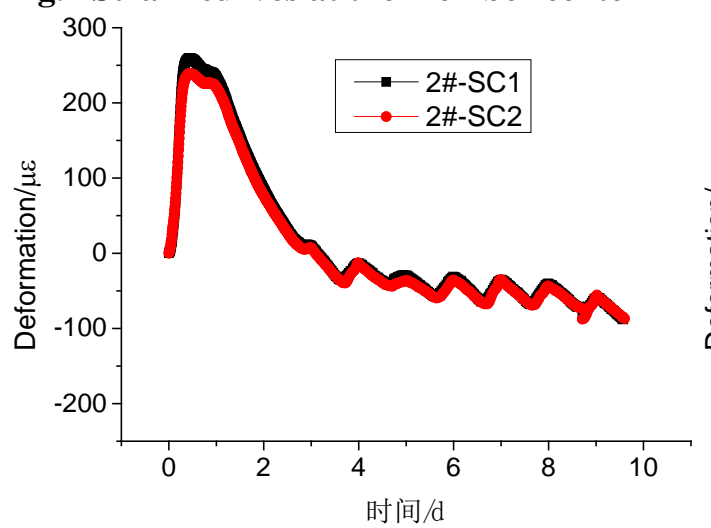

Fig.9 Strain curves at the member center

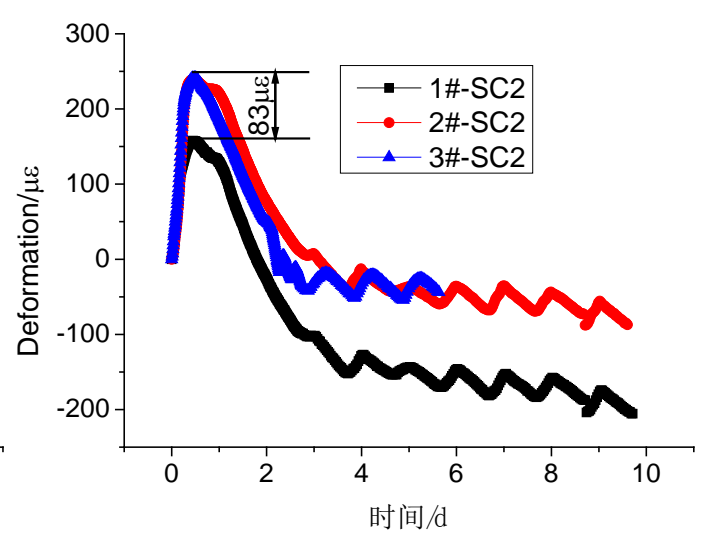

Fig.8 Strain curves on the member edge

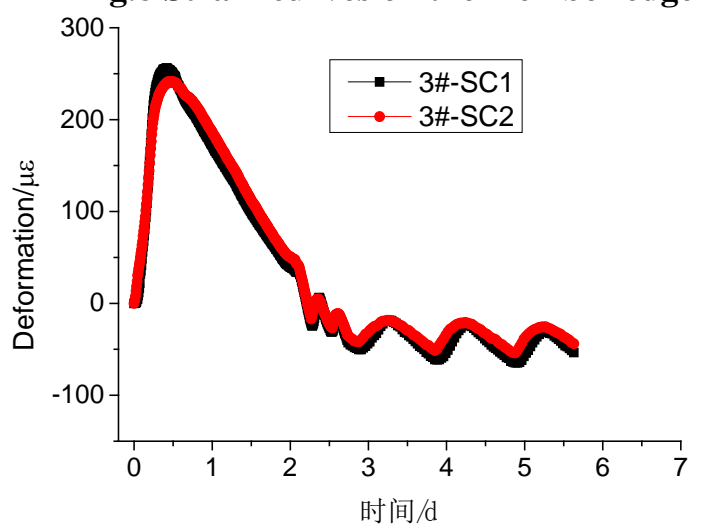

Fig.10 Strain curves on the member edge 


\section{Conclusions}

Tests are carried out in the outdoor and in situ in the paper. The real-time continuously curves of temperature and strain evolutions are obtained through monitoring concrete members in field since casting. The results were shown as follows:

At the very beginning, concrete temperature rises by $28^{\circ} \mathrm{C}$ in one day due to cement hydration, but it cooled down soon because of heat release and not being so thick, then temperature in the concrete members varied periodically with the change of the air temperature day and night, which is similar to the environment of wall. However, the farther the sensors were embedded away from the lateral surface, the smaller concrete temperature was impacted. Besides, because there was a certain expansion at early age, which can be considered as compensating shrinkage caused at later age in a certain extent so that minimum strain value is just about $-88 \mu \varepsilon$ which are not beyond the ultimate tensile strain. The maximum temperature rise of concrete prepared with new-anti cracking functional materials not only was reduced, but only there are reasonably expansive deformation at early age which can compensate later shrinkage, which can benefit avoiding cracking. The data from monitoring can provide helpful reference for the use of new-anti cracking functional materials , and also can be used to verify the effectivity of regulating temperature and deformation, which is available in the future for reference to use in similar projects and research.

\section{Acknowledgements}

This work was financially supported by the Technological Development Program of China Railway (Grant No. 2014G001-C). The authors gratefully acknowledge to the colleagues in program team, thanks very much for their hard work. The authors also acknowledge to the help of cooperate from some construction companies.

\section{Reference}

[1] Zhenhai Guo: Principles of reinforced concrete (Tsinghua University Press, Beijing 1999).

[2] P. K. Mehta: Cem: Concr. Res. Vol. 3(1) (1973), p. 1-6.

[3] G. M. Idom: Cem. Concr. Res. Vol. 22(6)(1992), p. 1039-1046.

[4] S. Chatterji: Journal of Crystal Growth. Vol. 277(2005), p. 566-577.

[5] P. Gao, S. WU: Construction and Building Materials. Vol. 21(2007), p. 132-138.

[6] C. Maltese, C. Pistolesi. A. Lolli et al.: Cem. Concr. Res. Vol. 35(2005), p. 2244-2251.

[7] W. Nocun-Wczelik, Z. Konik, A. Stok: Construction and Building Materials. Vol. 25(2011), p. 939-943.

[8] Fang-Xian Li, You-Zhi Chen and Shi-ZongLong: The Arabian Journal for Science and Engineering. Vol. 35(1B) (2010), p. 125-139.

[9] R. Troli, M. Collepardi, in: Proceedings of 4th International Conference on "Non-Traditional Cement \& Concrete”, Brno (Czech Republic) (2011), 27-30.

[10] L. Mo, M. Deng, A. Wang: Cement and Concrete Composites. Vol. 34(3) (2012), p. 377-383.

[11] Feng Jian, Lv Zhitao, et al.: Journal of Building Structures. Vol. 22(6) (2001), p. 14-19.

[12] Li Lijuan1, LU Weiwen, et al.: Journal of Building Structures. Vol. 2(2004), p. 114-120.

[13]Ting Yao, Qian Tian, et al.: Applied Mechanics and Materials. Vol. 351-352(2013), p. 1217-1221.

[14] Qian Tian, Yujiang Wang et al.: China Concrete and Cement Products. Vol. 5(2014)), p. 20-24. 
[15] HAN Xiyun, YUAN Zhigang, et al.: New Building Materials. Vol. 41(1) (2014), p. 39-41. 